\title{
PRODUÇÃO TEXTUAL DE ALUNOS DO 9 ANO DE UMA ESCOLA ESTADUAL DE IPIRANGA DO NORTE/MT
}

\author{
Rita de Cássia de Araújo SILVA ${ }^{1}$ \\ Mestrado Profissional/ PROFLETRAS-Universidade do Estado de Mato Grosso
}

\begin{abstract}
RESUMO:O presente texto faz parte de um projeto de pesquisa realizado através da disciplina de "Aspectos Sociocognitivos e Metacognitivos da leitura e da escrita", o qual apresenta o desenvolvimento e resultados de atividades de produção textual realizadas com os alunos do $9^{\circ}$ ano B, da Escola Estadual André Antônio Maggi, localizada no município de Ipiranga do Norte/MT, local em que trabalho como professora de Língua Portuguesa e tive a oportunidade em desenvolvê-lo. O trabalho tem como objetivo analisar situações entre a prática docente e a qualidade da produção textual, evidenciar a importância do trabalho prévio em sala de aula, com atividades que sejam capazes de oportunizar aos educandos momentos de planejamento, produção-reflexão, revisão e reescrita textual, e analisar a evolução dos textos produzidos pelos alunos, e as refacções textuais a partir da correção textual-interativa. As fontes científicas utilizadas para o embasamento teórico foram artigos e livros tendo como autores: Ruiz (2013), Passarelli (2012), Abaure e Abaure (2013),Wachowicz (2012), Geraldi (2014). A pesquisa realizada é de cunho qualitativo. Sendo assim, este trabalho nos proporcionou uma valiosa troca de experiências, reflexão e construção de conhecimentos.
\end{abstract}

PALAVRAS-CHAVE: produção textual; planejamento; escrita

\begin{abstract}
This text is part of a research project conducted through the discipline of "social cognitive and metacognitive aspects of reading and writing," which presents the development and results of textual production activities with students in 9th grade B School state André Antonio Maggi, in the city of Ipiranga do Norte / MT, where they work as a teacher of language and had the opportunity to develop it. The study aims to analyze situations between teaching practice and the quality of textual production, draw attention the importance of previous work in the classroom with activities that are able to create opportunities for learners moments of planning, production, reflection, revision and textual rewriting and analyze the evolution of the texts produced by the students, and the textual refacções from the textual-interactive correction. The scientific sources used for the theoretical basis were articles and books having as authors: Ruiz (2013), Passarelli (2012), and Abaure Abaure (2013), Wachowicz (2012), Geraldi (2014). The research is qualitative nature. Thus, this work has given us a valuable exchange of experiences, reflection and knowledge construction.
\end{abstract}

Key words: text production; blannin; writing

${ }^{1}$ Professora formada em Letras

Mestranda pelo Profletras - Campus de Sinop - MT 


\section{Introdução}

Este artigo tem como objetivo apresentar análise de atividades que visam oportunizar aos alunos condições para que sejam capazes de produzir textos, e, que possam aperfeiçor a escrita através do planejamento, escrita, reflexão e reescrita.

A escrita é um objeto social, e se concretiza em situações práticas com o convívio com outras pessoas, a partir dos diversos gêneros discursivos como cartas, e-mail, certidões de nascimento, casamento, lista de compras, recibos entre outros que fazem parte de nosso dia a dia, assim como podemos perceber na fala de Abaurre e Abaurre ( 2012, p.9 ). " A vida em uma sociedade letrada é marcada pelo contato com textos dos mais variados gêneros discursivos". Sendo assim nada mais justo que trazer os mais diversos gêneros textuais para a sala de aula.

Este trabalho proporcionou momentos de reflexão sobre minha prática como docente, pois para realizá-lo pesquisei sobre o assunto. Durante a leitura recordei da fala de colegas que afirmavam que os alunos tinham dificuldade em escrever, e percebi que esta fala também fazia parte do meu discurso, recordei de relatos dos próprios alunos que afirmavam que na hora de escrever acabavam se enrolando com as ideias e não escrevendo o que realmente queriam.

A partir de então pensei em realizar um trabalho que mostrasse que a tarefa da escrita e reescrita poderia ajudar a superar esses obstáculos, principalmente se descobrisse onde estava falhando em minha prática, e que pudesse mudar o meu discurso e o discurso de alguns alunos. Assim, comecei meu trabalho, pois como nos afirma Passarelli, (2012, p.44) “...escrever não é tanto uma questão de inspiração, mas de transpiração."

\section{Elaboração da proposta textual}

No dia 01 de outubro do ano de 2015, foi realizada a primeira atividade de produção textual, a temática utilizada foi os perigos do uso do celular no trânsito: como sabia que era um tema atual e polêmico considerei-o produtivo para trabalhar com os alunos. Porém, na primeira etapa da produção não utilizei nenhuma informação que pudesse facilitar a escrita, nesta aula utilizei somente uma charge, que foi retirada da internet, a qual possuia a temática relacionada ao uso do celular por condutores de veículos. A proposta de produção apresentava o seguinte enunciado: "Com base na leitura da tira, escreva um artigo de opinião."

O objetivo neste momento era questionar após a produção as dificuldades enfrentadas pelos mesmos, perguntei se eles acharam o tema difícil, se eles também tiveram dificuldade em produzir o artigo de opinião, se sabiam a diferença existente entre este gênero textual e outros gêneros. Alguns alunos afirmaram que já haviam trabalhado com este gênero e que não tiveram dificuldade, entretanto outros afirmaram que ainda possuem certa dificuldade em identificar as características deste gênero e produzi-lo.

A partir destes questionamentos comentei com os alunos que nem sempre a escrita é um dom, mas sim consequência de um planejamento, que para se escrever bem é necessário conhecimento referente ao assunto, à estrutura textual, estilo e conhecimentos linguísticos. Em seguida comentei se eles concordavam em fazer novamente o texto, e que esta produção seria dividida em etapas, momentos para busca de conhecimento referente à temática, à composição textual e outros aspectos linguísticos necessários para uma boa produção. Os 
alunos concordaram com os questionamentos e perceberam o quanto é importante o conhecimento prévio para um bom desenvolvimento das produções textuais.

Tal reflexão foi possível a partir da retórica sobre o discurso e natureza da linguagem, que nos apresenta que todo texto possui sua temática própria, assim como suas características de construção textual e estilo, como podemos ver na afirmativa de Bakhtin (1992, p. 279).

A utilização da língua efetua-se em forma de enunciado ( orais e escrito), concretos e únicos, que emanam dos integrantes duma ou doutra esfera da atividade humana. O enunciado reflete as condições especificas e as finalidades de cada uma dessas esferas, não só por seu conteúdo (temático) e por seu estilo verbal, ou seja, pela seleção operada nos recursos da língua recursos lexicais, fraseológicos e gramaticais, mas também, e sobretudo, por sua construção composicional. Estes três elementos ( conteúdo temático,, estilo e construção composicional) fundem-se indissoluvelmente no todo do enunciado, e todos eles são marcados pela especificidade de uma esfera de comunicação. Qualquer enunciado considerado isoladamente é claro, individualmente, mas cada esfera de utilização da língua elabora seus tipos relativamente estáveis de enunciados, sendo isso que denominamos de gênero do discurso.

Partindo da concepção de Bakhtin, é interessante fazermos uma reflexão sobre a língua, e questionarmos que quando escrevemos, escrevemos algo a alguém, com alguma finalidade. Então, por que muitas vezes a escola utiliza a produção textual de maneira descontextualizada, e com o único objetivo de correção? Se analisarmos estes questionamentos, seremos capazes de identificar as causas das dificuldades encontradas pelos alunos, e assim saná-las tornando as aulas de produção textual mais significativas.

Este trabalho tem como proposta analisar o desenvolvimento das produções textuais dos alunos, etapa por etapa, como primeiro passo recolher a primeira produção que foi organizada, sem planejamento, e informações prévias da temática, estrutura textual, para que sirva como material para comparação com os outros textos produzidos.

\section{Proporcionar condições para a escrita}

Escrever exige conhecimento sobre composição, estrutura, temática, e também planejamento. Pensando nestes aspectos, foram organizadas aulas que visavam desenvolver tais aspectos, e foi utilizado como material de apoio o livro Produção escrita: Trabalhando com gêneros, Caderno do Formador, editora CEALE, 2005.

$1^{\mathrm{o}}$ aula

Objetivo: levantar hipóteses, a partir da oralidade questionar os alunos para que os mesmos sejam capazes de decidir para quem escrever e como escrever?

- Para quem o texto será escrito? (Quem é o leitor?)

- Para que escrevê-lo? (Qual o objetivo?)

- O que escrever? ( Assunto)

- Onde será publicado? ( No caso o artigo de opinião). 
Após conversa com os alunos ficou decidido que iriamos criar um blog, e neste blog poderíamos publicar o artigo de opinião e outros textos que poderiam ser divulgados a todos os alunos e professores da escola.

Esta atividade foi muito produtiva, pois a partir das hipóteses levantadas os alunos foram capazes de questionar quais seriam os leitores e pensar nas características e linguagem utilizadas pelos mesmos para que este artigo pudesse ser produzido.

$2^{\circ}$ aula

Objetivo: Oportunizar situações para que se identifiquem as características do gênero artigo de opinião.

Texto "As universidades estatais devem reservar vagas para os alunos de escolas públicas?" de Antônio Manoel dos Santos, Folha de São Paulo, 25 de setembro de 1996.

- Leitura

- Análise da estrutura do texto e identificar as principais características de um artigo de opinião.

- Qual a tese defendida?

- Quais os argumentos utilizados?

- Quais os contra argumentos?

- O autor contestou o próprio argumento?

- Você acha que questionar o próprio argumento é uma estratégia importante?

$3^{\circ}$ aula

Objetivo: proporcionar situações de uso de conectores que possibilitem articulação entre os argumentos.

(Caderno do professor, Olimpíadas de língua portuguesa, 2014, p.112)

Nsta aula foram realizadas atividades reflexivas, apresentando o uso dos conectores e sua importância na produção textual.

$4^{\mathrm{o}}$ aula

Objetivo: Pesquisar informações para a produção textual.

Nesta aula os alunos trabalharam buscando informação referente a temática. No laboratório de informática pesquisaram diversos sites e anotaram informações que poderiam ser utilizadas na produção de seus argumentos.

$5^{\circ}$ aula

Objetivo: Produzir o artigo de opinião.

Nesta aula os alunos colocaram em prática as informações obtidas anteriormente. E a produção realizada neste segundo momento apresenta uma grande diferença em relação o primeiro texto, que propositalmente foi solicitado sem o planejamento, para que fosse comparado com o segundo texto, em que foram desenvolvidos os conhecimentos prévios. 


\section{A importância dos conhecimentos prévios}

O questionamento feito anteriormente, trouxe aqui os textos de um dos alunos, que demonstra a importância do trabalho com a composição textual, temática, questinamentos das características de quem será o leitor, o trabalho com os elementos articuladores e os conectores, O que podemos confirmar na fala de autoras Abaurre e Abaurre, ( 2012, p.23) de que "Deve-se partir do princípio de que não é possível produzir bons textos sem informações prévias."

O trabalho com produção textual envolve o desenvolvimento de várias habilidades que devem ser trabalhadas, o professor precisa proporcionar situações para que o aluno construa tais conhecimentos, propondo atividades propícias para que o estudante seja capaz de refletir e aperfeiçoar a sua escrita, o que em alguns casos não ocorre, causando assim a falsa impressão de que muitos alunos não sabem escrever.

Para Passarelli ( 2012, p. 46), isto é herança da forma como muitos de nós aprendemos a escrever com base nas tradicionais "técnicas básicas de redação", em que mostravam-nos um texto de um autor consagrado e diziam: "Isto é um texto narrativo". "Escreva um texto narrativo". E a escola ensinava três tipos de textos - o descritivo, o narrativo, e o dissertativo.

Hoje esta realidade mudou. Dolz e Schneuwly (2004) nos trazem a proposta do trabalho com vários gêneros do discurso que fazem parte do nosso contexto social como se pode ver na tabela a seguir, citada por Abaurre e Abaurre (2012, p. 20).

\begin{tabular}{|l|l|}
\hline TIPOS DE COMPOSIÇÃO & EXEMPLOS DE GÊNEROS DOS DISCURSOS (ESCRITOS) \\
\hline NARRAÇÃO & $\begin{array}{l}\text { Conto de fadas, conto maravilhoso, fábula, narrativa de aventura, } \\
\text { narrativa de ficção cientifica, narrativa de mistério, Sketch (breve } \\
\text { cena cômica), biografia, autobiografia, relato de viagem, crônica } \\
\text { (social, esportiva, literária, etc), piada, notícia, etc. }\end{array}$ \\
\hline ARGUMENTAÇÃO & $\begin{array}{l}\text { Editorial, artigo de opinião, carta ao leitor, carta aberta, carta de } \\
\text { reivindicação, resenha, anúncio publicitário, charge, cartum, fôlder, } \\
\text { etc. }\end{array}$ \\
\hline EXPOSIÇÃO & $\begin{array}{l}\text { Texto didático, texto de divulgação cientifica, verbete, entrevista, } \\
\text { reportagem, relatório, apresentações em Power Point, etc. }\end{array}$ \\
\hline INJUNÇÃO & $\begin{array}{l}\text { Regra de jogo, receita, regulamento, instruções de uso de montagem, } \\
\text { etc. }\end{array}$ \\
\hline
\end{tabular}

Tabela 1: Tipos de Composições textuais

O trabalho com produção textual, precisa ir além das técnicas de redação, em que só existia a narração, descrição e dissertação, e que os textos só precisavam ter início, meio e fim. A partir de tal perspectiva trago agora dois textos de um único aluno, no primeiro texto foi apresentado propositalmente a proposta textual com uma tira e com o enunciado "Com base na tira, escreva um artigo de opinião", em que não foi oferecido ao aluno conhecimentos 
prévios referente à temática e composição textual. E em seguida o texto do mesmo aluno, após o trabalho com atividades que visavam desenvolver a temática, a estrutura textual do gênero artigo de opinião. O aluno será identificado apenas com as iniciais do seu nome, e sua idade.

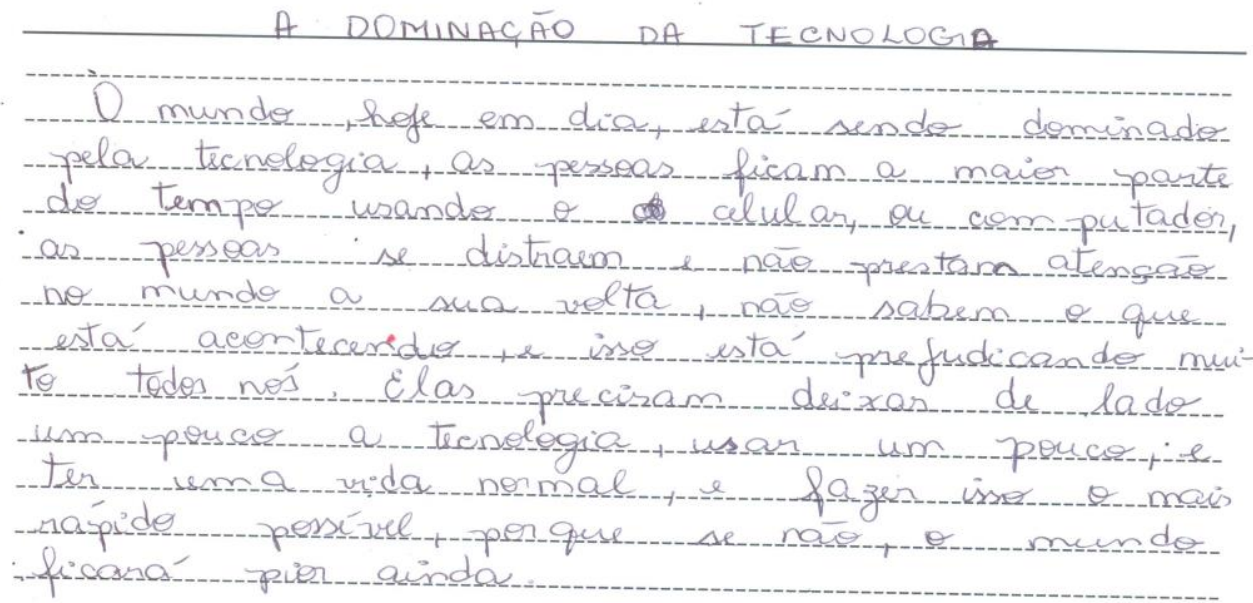

TEXTO I ( aluno B. H. 15 anos)

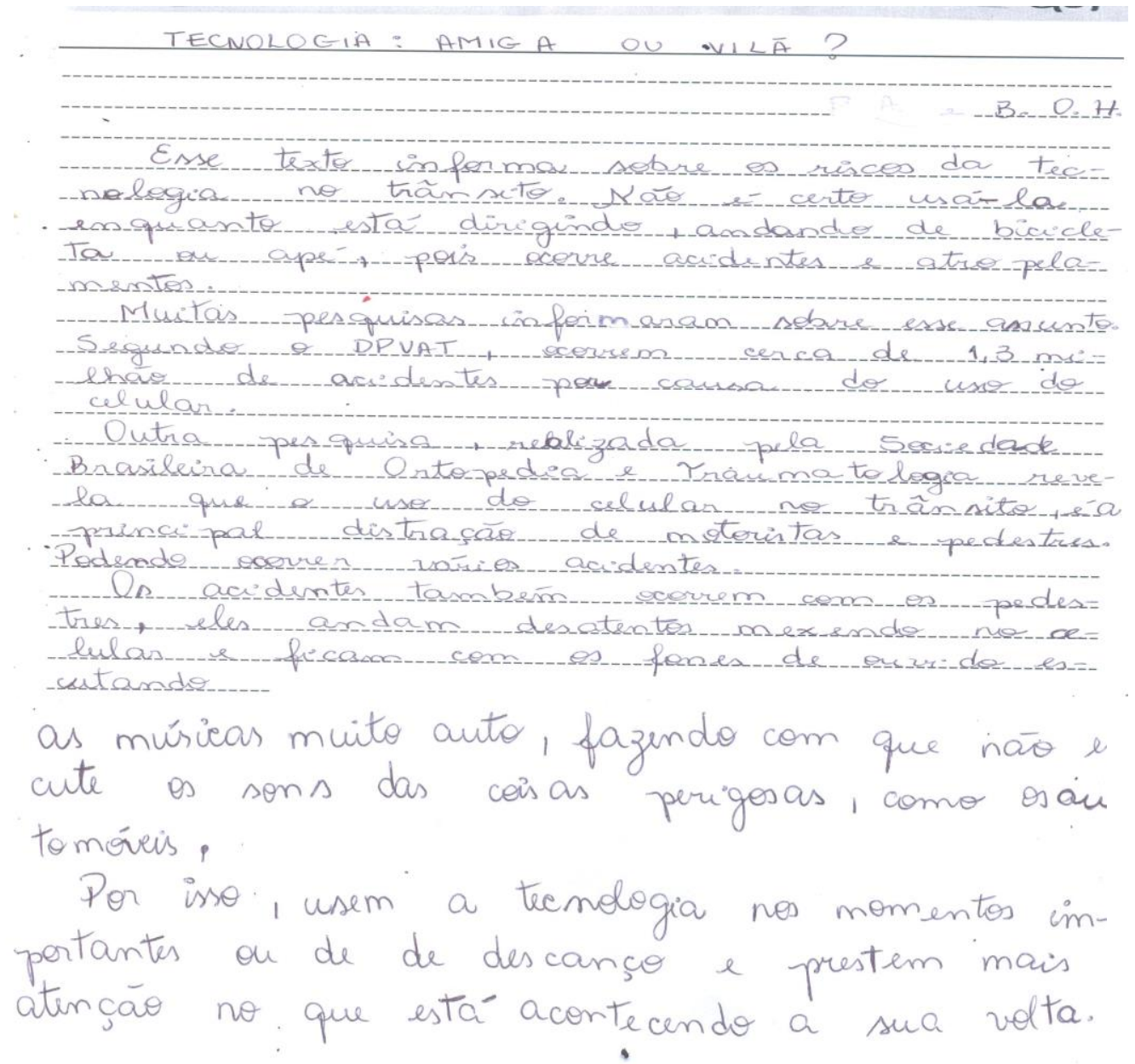


Texto II( aluno B. H. 15 anos)

O texto I e o texto II, foram produzidos pelo mesmo aluno, no primeiro texto foi entregue a proposta da produção textual, e não foi proporcionado nenhum conhecimeto prévio para o aluno. Já no segundo texto foi trabalhado com o aluno a composição textual do artigo de opinião, as características que fazem parte deste gênero textual, assim como momentos em que o aluno pode pesquisar sobre a temática exigida. Também foi decidido entre os alunos que eles iriam publicar o texto no blog da escola, o que proporcionou-lhes significado real para produção.

Ao comparar o primeiro texto com o segundo pode-se observar a evolução da produção textual deste jovem em relação a organização dos argumentos, o desenvolvimento da temática, a estrutura textual. Evolução esta que foi possibilitada a partir dos conhecimentos prévios adquiridos e o respeito as etapas que fazem parte do processo da produção textual. Como pode-se constatar na fala de Abaure e abaure (2012, p.45).

Não se pode, portanto,ignorar o fato de que qualquer texto é elaborado em diferentes etapas, durante as quais a atenção do aluno se voltou para aspectos estruturais, temáticos e linguísticos. Faz sentido, pois, procurar meios que permitam considerar os diferentes elementos constitutivos de um texto no momento de sua avaliação.

Podemos evidenciar a importância do trabalho do professor como mediador do conhecimento, preparando e oportunizando situações de aprendizagem.

O segundo texto possui alguns problemas relacionados a ortografia e outros aspectos relacionados a norma culta, critérios estes que fazem parte da próxima etapa do trabalho que são: leitura,reflexão e refacção.

\section{Leitura, reflexão e refacção}

O momento da reescrita é essencial no processo da escrita, pois o mesmo desenvolve a prática de reler, refletir e modificar o texto. Este processo deve ser acompanhado e em alguns casos até conduzidos pelo professor, sendo um trabalho desenvolvido entre professor e aluno. O professor deve exercer o papel de mediador como pode-se observar na fala de Ruiz:

O trabalho de retextualização realizado pelo aluno que revisa em função de uma correção do professor não é um trabalho solitário, como a principio pode parecer (muito embora a solitude da tarefa de escrita lhe seja imanente). Esse seu trabalho é, necessariamente, e pela própria natureza, um trabalho a quatro mãos. De modo que toda e qualquer consideração que se faça a respeito do maior ou menor sucesso do aluno na tarefa de revisão (retextualização) deve inalienavelmente levar em conta a participação efetiva do mediador ( o professor) no processo como um todo.( RUIZ, 2013, p.26)

Como pode-se observar na fala de Ruiz, a correção textual é um proccesso em que trabalham juntos aluno e professor, sendo assim, é muito importante a escolha do método adotado para correção. A autora apresenta quatro concepções de correção textual em sua obra, 
sendo elas: A correção indicativa, a correção resolutiva, a correção classificatória, e a correção textual-interativa.

Sendo a correção textual um momento de interação entre aluno e professor, a metodologia utilizada para este trabalho foi a textual-interativa, pois apresenta comentários longos e um nível maior de comunicação. Como apresenta Ruiz.

Trata-se de comentários mais longos do que os que se fazem na margem razão pela qual são geralmente escritos em sequência ao texto do aluno ( no espaço que aqui apelidei de "pós-texto" ). Tais comentários realizam-se na forma de pequenos "bilhetes"... Esses "bilhetes", em geral, têm duas funções básicas: falar acerca da tarefade revisão pelo aluno (ou mais especificamente, sobre os problemas do texto), ou falar, metadiscursivamente, acerca da própria tarefa de correção pelo professor. (RUIZ, 2013, p.47).

Esta atividade foi desenvolvida da seguinte maneira: eles produziam os textos em uma aula e eu os corrigia e os trazia juntamente com os bilhetes para a próxima aula, para que desta maneira pudessem reler, refletir e revisar o texto em sala de aula. O intuito desta atividade era questiná-los, instigá-los, e a partir de então estaria sempre atenta para mediar os trabalhos e tirar as dúvidas, pois a atividade de reescrita deve ser um trabalho desenvolvido em sala de aula, com a interação professor-aluno, para oportunizar ao aluno situações em que possam perceber que a revisão e a refacção fazem parte do processo da escrita.

Para complemetar o trabalho, no momento em que entreguei os textos e os bilhetes, também entreguei uma ficha de autoavaliação, ficha esta que foi desenvolvida de acordo com o caderno do professor (Olimpíadas de língua portuguesa, p.147), pois o intuito era fazer com que os alunos pudessem identificar em seus textos o que precisaria ser alterado. Até então eles achavam que seria somente a parte ortográfica e pontuação, ou algum outro critério da norma culta. Os bilhetes foram uma novidade para eles, assim como para mim, pois até então os textos eram corrigidos na própria folha, onde era grifado o que precisava ser alterado. Este tipo de correção é diferente, muito interessante e construtiva.

Por tratar-se de uma estratégia nova, os alunos começaram a solicitar explicações, pois o bilhete só trazia questinamentos como: "Leia o texto e veja se não ocorreu fuga ao tema", "veja se a estrutura está de acordo com o artigo de opinião ou organize seus argumentos". Tais questionamentos os ajudaram a desenvolver uma visão questionadora, pois até então os textos que eles produziam eram grafados com a exigência de que eles o corrigissem. A correção era feita em casa para ser entregue na próxima aula, muitos perdiam os textos e acabavam não corrigindo, ou acabavam refazendo o que o professor já havia feito, como no caso da correção da ortografia de certas palavras em que o professor grifa o texto e escreve corretamente a palavra para mostrar ao aluno qual seria a ortografia correta.

Uma experiência que foi muito construtiva na correção textual-interativa foi a interação entre professor e aluno. Como atividade solicitada havia sido a produção textual de um artigo de opinião que os alunos iriam desenvolver a partir de uma charge, debatemos o assunto e pesquisamos no laboratório de informática. Porém, mesmo com todas estas informações alguns alunos apresentavam algumas dúvidas em relação ao desenvolvimento do texto, organização dos argumentos ou desenvolvimento da temática, foi o que aconteceu no texto que será apresentado a seguir. 


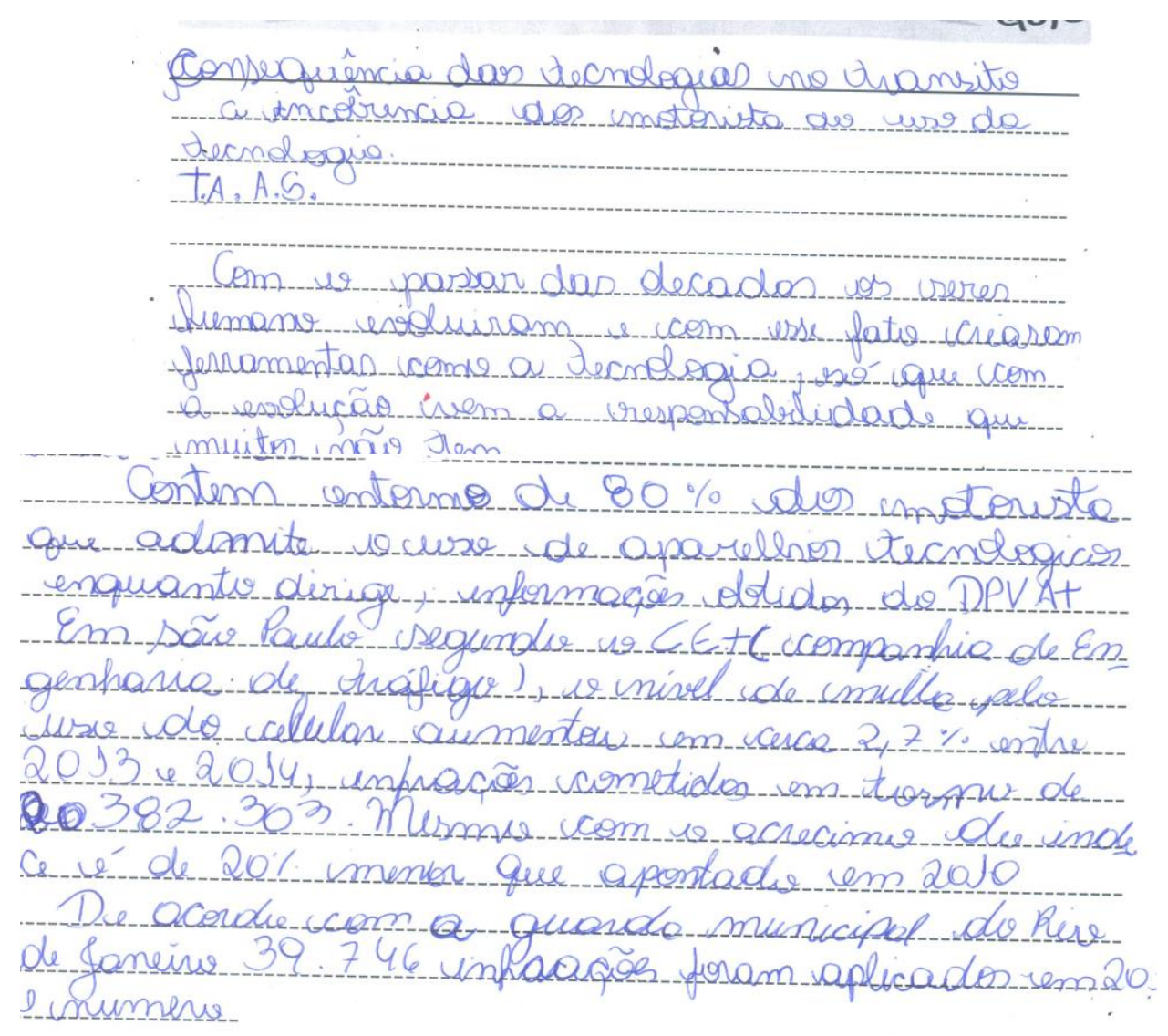

Texto I ( aluna T. A. A. S.)

Como pode-se observar nesta produção textual, o texto não está bem estruturado, os argumentos não estão organizados, as informações que foram adquiridas com a pesquisa aparecem soltas, sem que o autor defenda sua tese, não possui conclusão, e algumas palavras não foram acentuadas. Sendo assim foi solicitado a partir do bilhete que estes critérios fossem revistos. Como pode ser observado no bilhete que vem a seguir.

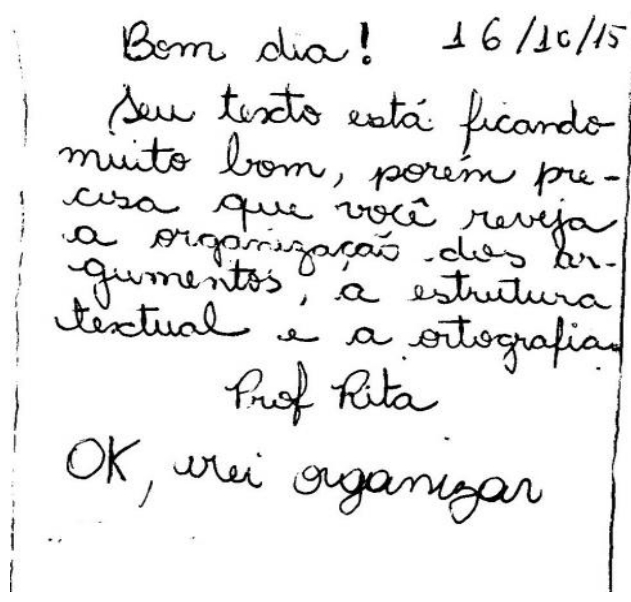

Bilhete I 
A partir de observações que pude constatar na segunda produção, posso afirmar que esta atividade oportunizou ao aluno ler o texto com um olhar não de quem estava produzindo, e sim como de alguém que estava corrigindo, construiu questionamentos, que foram compartilhados com o professor que se tornou um mediador, o qual foi apresentado outros artigos, para que o aluno observasse a estrutura textual e comparasse com a do texto que havia produzido e então veio o segundo texto.

Celular e trânsito: Näo combinam!

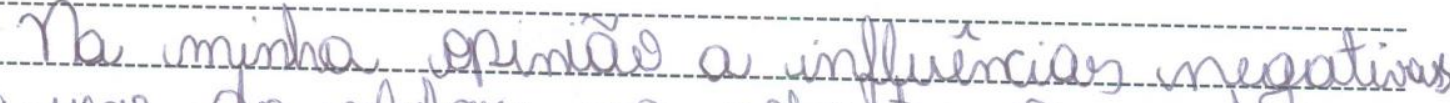
do wos de celular no vslente. aumentoram

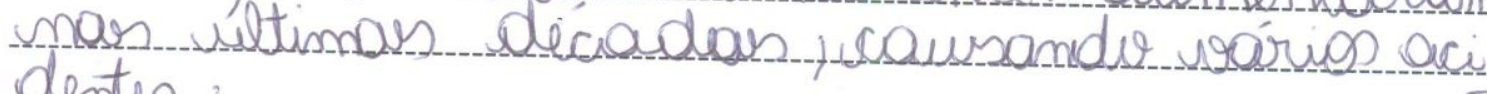
dentes

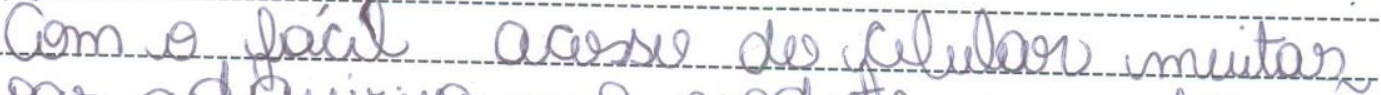

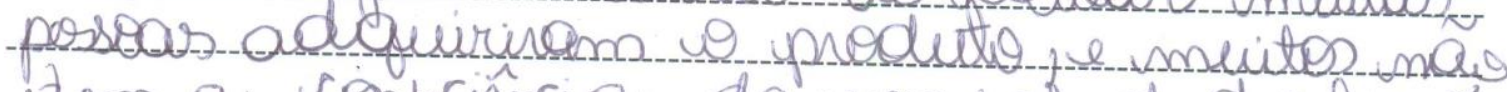

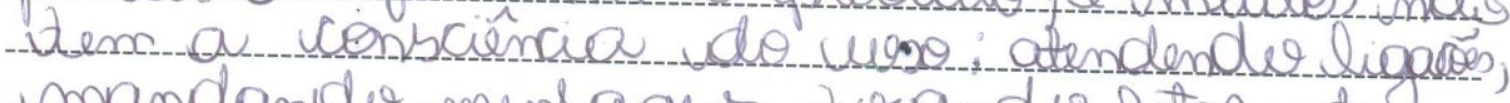
- mandande memsagens zirando foton nt se

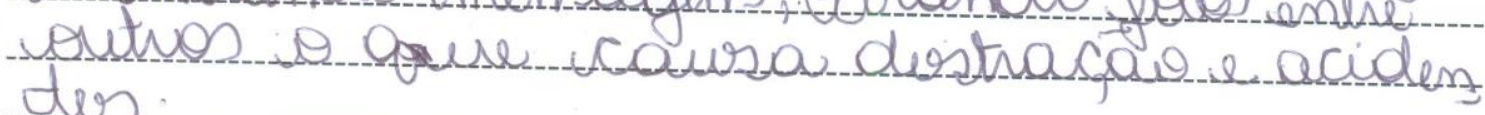
des

1) e-acondo ccom pesquisas al cérelse?

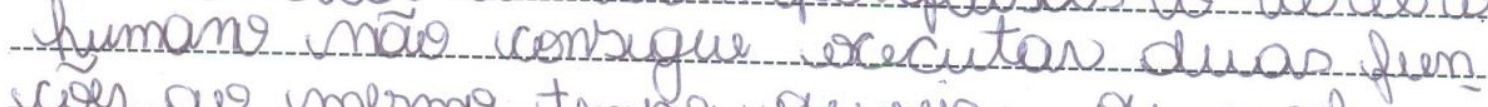

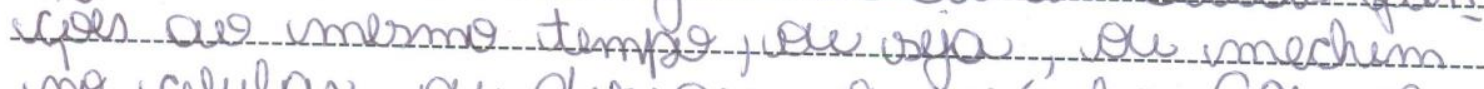

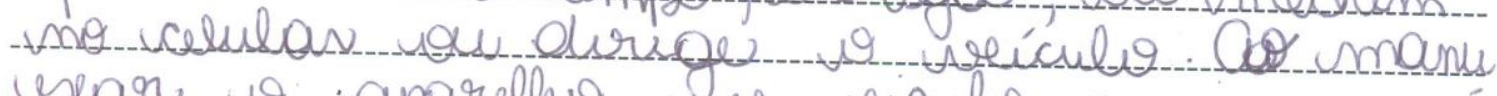

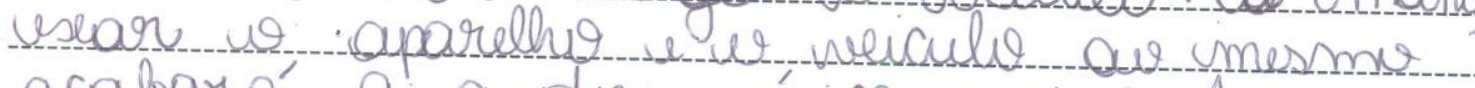

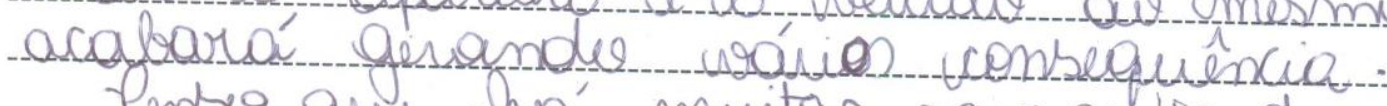

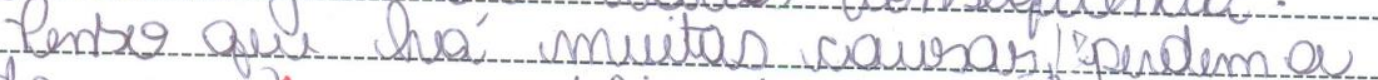
Ardo tros mam deficientes pis tisam a yrde de Altrar pessegr-b destrumdo fomalios. Q Contecimentos ople aDul podem ser mudado

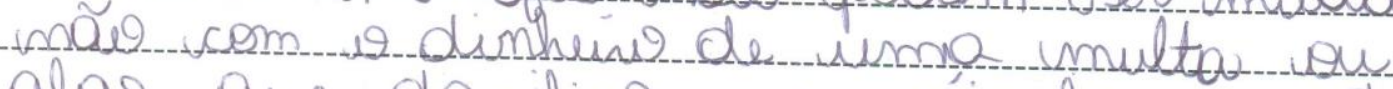

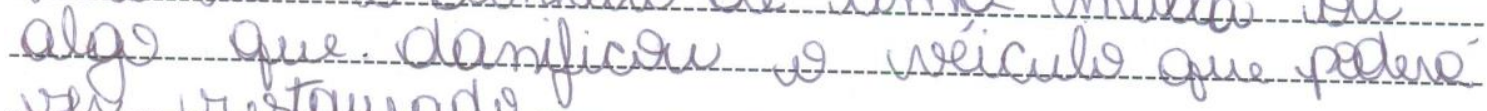
ver restomsade

Com andir combcrencios nomenos acidentes

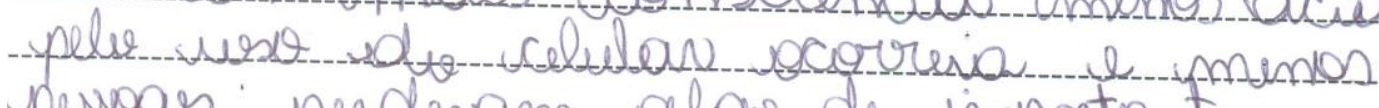

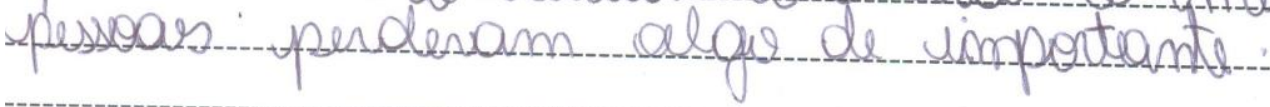




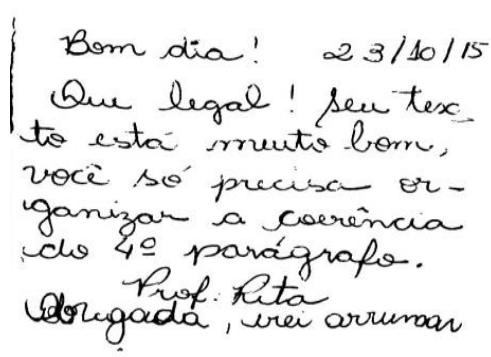

\section{Bilhete II}

Neste texto pode-se perceber o desenvolvimento do aluno, em relação a organização textual, organização das ideias presentes nos argumentos, e acentuação sendo que o texto ainda apresenta incoerência no quarto parágrafo, e o bilhete apresenta elogios e a indicação sobre o que precisa ser alterado. Neste segundo bilhete assim como nos demais, além dos questionamentos, são apresentados elogios e frases que motivam o aluno, pois como podemos observar na fala de Libâneo para alcançar os processos do ensino é importante desenvolver além dos aspectos cognoscintivo o aspecto socioemocional, em que os bilhetes são utilizados como ferramentas par se alcançar este objetivo.

Para alcançar os objetivos do processo do ensino: a transmissão e assimilação dos conhecimentos hábitos e habilidades". Enfatizem -se em especial dois aspectos no trabalho docente: " $\mathrm{O}$ aspecto cognoscitivo ( que diz respeito a forma de comunicação dos conteúdos escolares e às tarefas escolares indicas aos alunos) e o aspecto socioemocional ( que diz respeito às relações entre professor e aluno e às normas interdisciplinares indispensáveis ao trabalho docente).(Libâneo apud Passarelli, 2012, p.80)

Após várias etapas, podemos observar o desenvolvimento das habilidades deste jovem a partir da análise do terceiro texto em relação aos primeiros. 


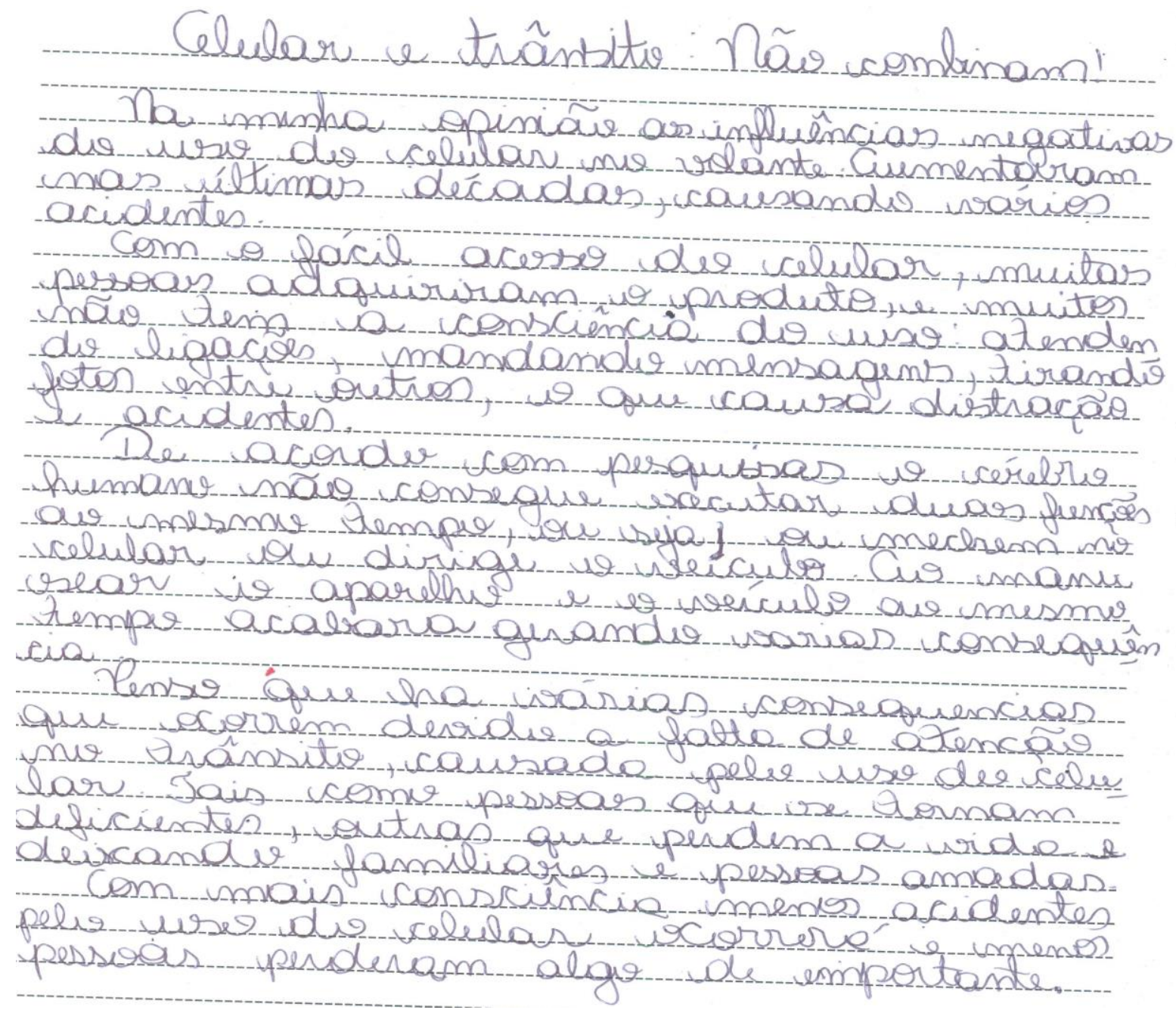

Texto III (aluno T. A. A. S. )

No terceiro texto pode-se observar o desenvolvimento do aluno em relação a sua produção, porém a produção ainda apresenta alguns problemas em relação a ortografia e pontuação. O que sugere um trabalho de reflexão e autocorreção. Como proposta o professor poderá circular ou grifar as palavras que foram escritas de forma inadequada e solicitar que o aluno utilize o dicionário e veja o que precisa ser alterado.

\section{Metacognição e produção textual}

Produzir textos nem sempre é simples, envolve várias etapas, e principalmente reflexões, para se chegar a um produto final de qualidade. No entanto é indispensável desenvolver a compreensão do processamento cognitivo, a denominada metacognição a capacidade do ser humano de monitorar e auto regular os processos cognitivos( JOU e SPERB, 2006). Sendo assim, acredito que a correção textual-interativa seja uma grande aliada para desenvolver a cognição nos alunos, pois a mesma não traz soluções prontas e acabadas, ela desenvolve no aluno um espirito questionador devido as reflexões feitas durante a revisão, 
pois várias vezes o sujeito reve seu texto e refleti sobre suas ações e avalia o que precisa ser alterado, pois em tal método de correção o professor questiona, ao invés de dar soluções sobre a problemática, fazendo assim com que o sujeito reveja suas ações até chegar ao produto final.

A partir de tal perspectiva observei que os alunos criavam estratégias metacognitivas na hora de produzir e principalmente durante a correção, e ao analisar o textos do aluno T. A. A. S , pode-se notar tais aspectos, observando o progresso textual apresentado pelo aluno, pois ao avaliar o primeiro texto nota-se que ocorre a necessidade de estruturar o texto e organizar os argumentos. Depois de reflexões e, questionamentos o aluno apresenta um texto com uma estrutura adequada ao gênero e organização dos argumentos.

\section{Considerações finais}

A proposta apresentada neste texto consiste em discutir e analisar a necessidade de um trabalho que fundamente e busque estratégias para que os alunos sejam capazes de construir o conhecimento referente a produção textual conscientizando-os da importância do planejamento, da revisão, da correção, no caso a textual-interativa, que a meu ver questiona os alunos, levando-os a construir estratégias metacognitivas e assim levá-los a compreender que todos estes processos citados anteriormente fazem parte do processo da produção textual.

Acredito ser fundamental que durante o momento do planejamento ocorra vários questionamentos, tais como: O que escrever? Como escrever? Para quem escrever? Sendo que esta última pergunta é necessária para tornar o texto significativo para o aluno. Deve-se pensar onde publicar o texto, em um blog, em um jornal da região, ou no mural da escola. Este é um critério importante para que se construa um novo significado para os textos produzidos na escola, para que se deixe de lado aquela visão de que o texto só serve para o professor corrigir atribuindo assim uma nota, e que logo após o aluno o rasgue ou o amasse e o jogue fora, ficando assim só no primeiro texto, sem se preocupar com a correção e a revisão. Devemos apresentar situações para que o aluno possa compreender que não é esta a função da escrita em nossa sociedade. Mostrar que o valor da escrita não pode ser simplesmente este, e sim apresentar e questionar situações que envolvam a escrita fora do ambiente escolar, para assim tornar a produção textual, e a aprendizagem em algo significativo.

\section{Referências bibliográficas}

ABAURE , M. L. M. ; ABAURE M. B. M. Um olhar objetivo para produções escritas: analisar, avaliar, comentar. São Paulo. Moderna,2012.

JOU, G. I.; SPERB, T. M. A Metacognição como Estratégias Reguladora da Aprendizagem.UFRGS,Disponível em www.sielo.br/sielo.php?pib Acesso em 12 de janeiro de 2016.

GERALDI, J. W.; O texto na sala de aula. São Paulo.Anglo, 2012.

PASSARELLI, L. M. G. Ensino e correção na produção de textos.Telos. 2012. 
RUIZ, E. D. Como corrigir redações na escola.São Paulo.Contexto.2013.

VAL, M. G. C. Produção escrita. Belo Horizonte. Ceale, 2007, Disponível em www.ceale.fae.ufmg.br Acesso em 11 de janeiro de 2016

WACHOWICZ. Análise linguística nos gêneros textuais. Saraiva. 2012. 